\title{
COMPARISON OF SUPRAMAXIMAL LEVATOR PLICATION WITH TARSO FRONTALIS SLING BY SILICON ROD IN SEVERE PTOSIS WITH POOR FUNCTION LEVATOR PALPEBRAE SUPERIORIS
}

\author{
Salil Kurnar Mandal'1, Purban Ganguly², Aparna Mandal ${ }^{3}$
}

${ }^{1}$ Associate Professor, Department of Ophthalmology, Regional Institute of Ophthalmology, Medical College, Kolkata, West Bengal, India.

${ }^{2}$ Clinical Tutor-Cum RMO, Department of Ophthalmology, Medical College, Kolkata, West Bengal, India.

${ }^{3}$ Associate Professor, Department of Physiology, College of Medicine and Sagore Dutta Hospital, Kolkata, West Bengal, India. ABSTRACT

\section{BACKGROUND}

Drooping of upper lid is commonly known as ptosis. It may be unilateral or bilateral. It may be congenital or acquired. We wanted to evaluate the functional and cosmetic correction, complications and recurrence of levator plication and compare the same with tarso frontalis sling with silicon rod in severe ptosis with poor function LPS.

\section{METHODS}

This is an institution based prospective, randomized, international comparative study of 40 eyes over a period of two years. Group A comprised of 20 eyes operated with levator plication of which three interrupted vertical mattress sutures with supra maximal plication of LPS. Group B comprised of 20 eyes operated with tarso frontalis sling with silicon rod.

\section{RESULTS}

Out of operated 40 cases, complications included significant inflammation and oedema in 1st post-operative week in plication Gr-A. Scar was more in plication Gr-A. In this study, 6 cases had not satisfactory (gross under correction) result in plication Gr. and one case in Gr. B. This was treated with readjustment of the sling. With respect to uplift or fixed lid height post operatively, comparison between $\mathrm{Gr}$ - A and Gr -B results shows that there was good uplift with brow up and brow down in Group B which is statically significant $(p<0.001)$. All the patients were followed up for six months to one year.

\section{CONCLUSIONS}

In severe ptosis correction, tarso frontal sling is superior than supramaximal plication of LPS with regard to complications like inflammation, oedema, scar and cosmetic lid height. From technical point of view, surgical procedure is much easier (minimal invasive) in Gr-B. with a period of one year follow up.

\section{KEY WORDS}

Ptosis, Lid Deformity, Lid

HOW TO CITE THIS ARTICLE: Mandal SK, Ganguly P, Mandal A. Comparison of supramaximal levator plication with tarso frontalis sling by silicon rod in severe ptosis with poor function levator palpebrae superioris. J. Evolution Med. Dent. Sci. 2019;8(28):22952298, DOI: $10.14260 /$ jemds/2019/502

\section{BACKGROUND}

Ptosis is drooping of upper lid. It may be congenital or acquired. Normally the upper eye lid margin rests about 2 $\mathrm{mm}$ below upper limbus. Ptosis is broadly classified into congenital and acquired. Congenital ptosis is due to failure of neuronal migration or development with muscle sequelae or it may be associated with $3^{\text {rd }}$ nerve misdirection, Marcus Gunn jaw winking syndrome or blepharophimosis syndrome. Acquired ptosis can be classified as neurogenic (innervational deficit), myogenic due to myopathy of the LPS muscle, or impaired transmission in neuromuscular junction. Aponeurotic ptosis (defect in the levator aponeurosis). Mechanical ptosis is due to gravitational effect of the mass. Ptosis is usually graded as mild (up to $2 \mathrm{~mm}$ ), moderate (up to $3 \mathrm{~mm}$ ) and severe ( $4 \mathrm{~mm}$ or more) $)^{1.2}$.

'Financial or Other Competing Interest': None.

Submission 18-06-2018, Peer Review 25-06-2018,

Acceptance 05-07-2019, Published 15-07-2019.

Corresponding Author:

Dr. Salil Kurnar Mandal,

183, R. N. Guha Road, Dum Dum,

Kolkata, West Bengal, India.

E-mail: salil_dum@live.com

DOI: $10.14260 /$ jemds $/ 2019 / 502$

\section{(c) $\bigcirc$ () $\ominus$}

Surgical correction is required if the ptosis occludes the visual axis causing amblyopia, if there is abnormal head posture or if there is cosmetic concern ${ }^{3}$. Severe ptosis is usually operated in one of the following ways A) Frontalis sling with fascia Lata which could either be autogenous, homogenous, fresh or banked sclera. B) Frontalis sling with artificial material like silicon rod, Marceline mesh, artificial suture (collagen polypropylene, silicon, silk, nylon monofilament) maximum levator placation or resection. Present study is being conducted to evaluate functional and cosmetic correction, recurrence, and complication in both the procedures of levator plication and Frontalis sling with silicon rod in severe ptosis with poor function LPS 4,5

\section{METHODS}

Study was conducted in a tertiary hospital from $1^{\text {st }}$ January 2008 to $31^{\text {St }}$ December 2009. This is an institutional based prospective randomized, interventional, comparative study of 40 eyes over a period of two years. This study is a comparison of two modalities of surgical treatment for severe ptosis the sample size was 40 patients in two group. In Group-A 20 patients who underwent supramaximal LPS plication and in Group-B 20 patients includes Tarso frontalis sling with silicon rod. Patients will be allocated to either arm of the study by computer generated randomization schedule. 


\begin{tabular}{|c|c|c|c|c|c|c|c|c|}
\hline 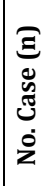 & 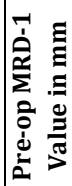 & 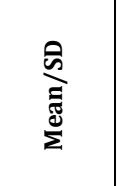 & $\begin{array}{l}\Xi \\
\vdots \\
\vdots \\
\vdots \\
0 \\
0 \\
\dot{0} \\
\dot{z}\end{array}$ & 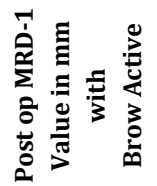 & हूँ के & 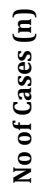 & 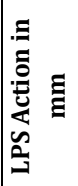 & 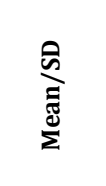 \\
\hline 7. & -3 & & 6 & +4 & & 5 & 5 & \\
\hline 10. & -2 & & 7 & +3 & & 6 & 4 & \\
\hline 02 & -1 & & 7 & +2 & & 9 & 3 & \\
\hline 01 & 0 & $-2.15 \pm 0.83$ & & & $+2.68 \pm 0.65$ & & & $3.84 \pm 1.31$ \\
\hline \multicolumn{9}{|c|}{$\begin{array}{l}\text { Table 1. Group-A (Supramaximal LPS application) Shows Measurement of } \\
\text { Preoperative. MRD-1 Values, Postoperative MRD -1 Values with Active } \\
\text { Brow Position, and LPS Action with Mean and Standard Deviation }\end{array}$} \\
\hline
\end{tabular}

\begin{tabular}{|c|c|c|c|c|c|c|c|c|}
\hline $\begin{array}{l}\Xi \\
\Xi \\
0 \\
\vdots \\
\tilde{z} \\
\dot{0} \\
\dot{z}\end{array}$ & 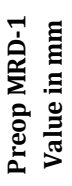 & 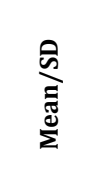 & 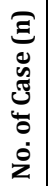 & 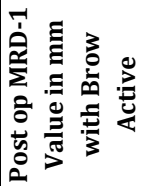 & 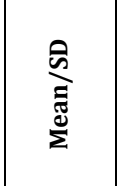 & 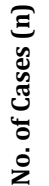 & 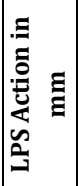 & 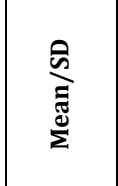 \\
\hline 10 & -3 & & 02 & 5 & & 4 & 5 & \\
\hline 06 & -2 & & 14 & 4 & & 7 & 4 & \\
\hline 03 & -1 & $-2.14 \pm 0.91$ & 4 & 3 & $+3.90 \pm 0.55$ & 7 & 3 & $+3.95 \pm 0.82$ \\
\hline 01 & 0 & & & & & & & \\
\hline
\end{tabular}

Table 2. Group-B (Tarso frontalis Sling with Silicon Rod) Shows Measurement of Preoperative MRD-1 Values, Postoperative MRD -1 Values with Active Brow Position, and LPS Action with Mean and Standard Deviation

\begin{tabular}{|l|}
\hline $\begin{array}{c}\text { Compare the Uplift of Upper Lid or Ptosis Correction in Both the } \\
\text { Groups } \\
\text { Group-B No of Cases }=20\end{array}$ \\
$\begin{aligned} & \text { Group-A No Cases }=20 \text { MRD- } 1 \text { Value }=+3.90 \\
& \text { MRD- } 1 \text { Value }=2.68 \text { Standard deviation }= \pm 0.55 \\
& \text { Standard deviation }= \pm 0.65 \text { Student } t \text { test for calculation of } p \text { value } \\
& \text { P }<0.0001 \text { Clinically significant } \\
& \mathrm{t}=6.6704, \text { df }=38\end{aligned}$ \\
\hline
\end{tabular}
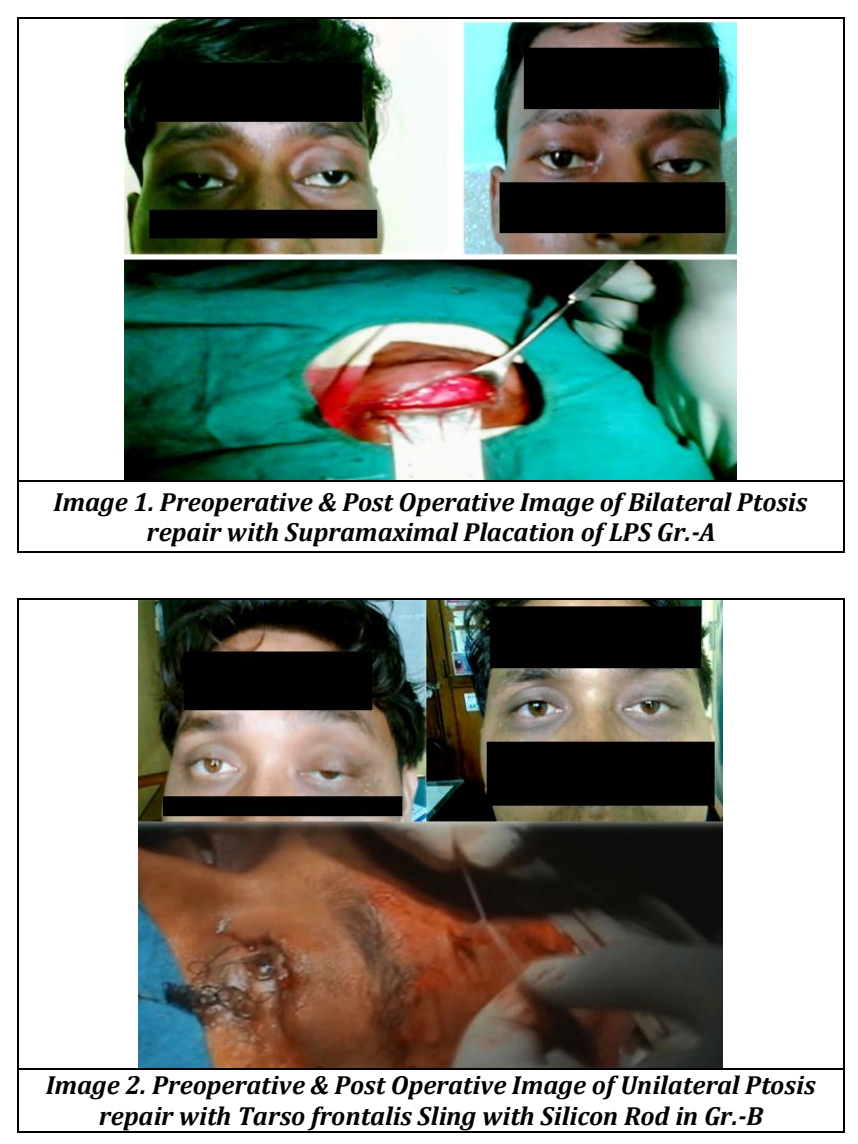

All the patients met the inclusion and exclusion criteria for the present study. The study population was then randomly distributed using block randomization technique into two study group. Group-A Supra maximal LPS plication 20 and Group-B Tarso frontalis sling with silicon rod -20 this is randomized, interventional control trial of 40 eyes over a period of two years. Of which $2 \mathrm{l}$ were males and 15 were females. Gr.-A 20 eyes operated with levator plication of which three interrupted vertical mattress sutures with ever maximal plication of LPS possible. Gr.-B 20 eyes operated with tarso frontalis sling with silicon rod.

A standard proforma was used to record history and examination-of the patient's data included the age of onset of the ptosis. it's duration, associated diplopia variability of the ptosis as the day progress or fatigability. Examination included estimation of visual acuity, pupillary light reflex, and inspection of chin elevation or head posture. Brow elevation Specific ptosis elevation included measuring the marginal reflex distance pre and post operative period in $\mathrm{mm}$. (normal value $4-4.5 \mathrm{~mm}$ ) Pre and post operative measurement of amount of ptosis or central vertical fissure height in primary position (Normal value is 9-1 $2 \mathrm{~mm}$ ). Levator function, measured in mm by upper lid excursion from down gaze to up gaze position while the frontalis function negated by placing the thumb firmly against the patient, brow. In this study Data collected from various patients statically analyzed step by step. Data entry was done in epidata version 3.1 and data analysis was done in SPSS version 20. Data are presented as mean \pm SD and $p$ value calculated with student $t$ test. The upper. Lid crease, absence of which indicate congenital ptosis. Extra ocular motility test examination to asses fatigability, jaw winking phenomenon, Bell's phenomenon, corneal sensitivity, tear film stability. In this study each subject allocated with either arm of the study by computer generated randomization scheduled. Also this study along with informed consent taken from each patient in each category of operation. Each patient must have inclusion and exclusion criteria for the selection of this study. Inclusion criteria was age between 5 to 45 years with no sex predilection, patient with congenital ptosis, severe ptosis, poor levator function less than $4 \mathrm{~mm}$, blepharophimosis syndrome.

Exclusion criteria's in this study were Patient with vertical squint, patient with abnormal or poor bell's phenomenon, Marcus Gunn jaw winking phenomenon, mild to moderate ptosis, history of previous ptosis surgery, corneal anaesthesia, nystagmus.

\section{Surgical Procedure}

Group-A Supra maximal Levator plication in severe ptosis. Three marginal lid suture applied, $3 \mathrm{~mm}$ above the upper lid margin horizontal incision made, incision deepen to exposed tarsal plate, orbital septum and LPS. Maximum vertical distance of LPS was measure approx 23to $24 \mathrm{~mm}$.Three mattress suture applied central medial and lateral anchoring tarsal plate to LPS muscle and plicate on tarsal plate. Vertical shortening of the lid or1ift up the ptotic eye lid.6,7,8 Frost suture applied for 5 days Group-B Surgical procedure Tarso frontalis sling with silicon rod, in severe ptosis Horizontal stab incision, made 18- $24 \mathrm{~mm}$ above superior orbital, rim at the central fore head which coincide with a line join central point of upper lid in primary gaze. Depth of incision up to 
periosteum. Then two supra brow stab incision made one at the junction of medial $1 / 3$ rd and middle $1 / 3^{\text {rd }}$ of the brow and another at the junction of the middle $1 / 3 \mathrm{rd}$ and lateral $1 / 3 \mathrm{rd}$ of the brow. The first three stab incision join to make a triangle. Then two stab incision made $3 \mathrm{~mm}$ above $5 \mathrm{~mm}$ left and right of the central point of the upper eye lid. All five-stab incision join to made the pentagon, which forms the way of passing silicon rod. Finally, silicon rod tighten to lift up upper lid just up to upper margin of limbus. The two-silicon rod pass through the silicon sleeve and transfixed with 6-0 proline suture- Central forehead incision undermined to accommodate the silicon rod under the skin. Frost suture applied for 5 days. ${ }^{9,10,11}$ In both of the group antibiotic eye ointment and lubricants used at postoperative period.

\section{RESULTS}

Out of 40 cases of ptosis Group-A 20 undergo supramaximal LPS Plication and Gr.-B undergo tarso-frontal sling with silicon rod. Of which 25 were males and 15 were females. In this study 24 cases were unilateral, and 16 case were bilateral.26 cases were simple congenital ptosis with poor function LPS. 12 cases had acquired ptosis and 2 cases with blepharophimosis syndrome. In Blepharochalasis syndrome telecanthus is repaired 6 month before by double $\mathrm{z}$ plasty with, medial canthal tendon shortening. All the patient had poor eye lid crease pre-operatively. Preoperatively all patients had severe ptosis with average margin to reflex distance (MRD-1) in Group-A -2.15 \pm 0.83 and Gr.-B $2.14 \pm 0.91 .1 \mathrm{n}$ all unilateral cases and in bilateral cases had average levator function measured. In Gr. A+ 3.84 \pm 1.31 and Group-B $3.95 \pm 0.82$. Amblyopia seen in 10 cases. In all cases average post operative MRD-1 with brow active position was In Group A +2.68 \pm 065 . and In Gr.-B +3.90 \pm 0.55 .After 6 months post operative period, in respect to uplift of the lid post operatively, comparison between $\mathrm{Gr}$ - A and $\mathrm{Gr}$-B results show there was good uplift with brow active position. In Gr.B which is stastically significant $(\mathrm{p}<0.0001)$ In all the cases post operatively no such over action of frontalis muscle in (Gr.-B) Tarso-frontal sling with silicon rod. But 6 cases in plication (Gr-A) had still frontalis over action. All the patient had good eye lid crease and satisfactory lid height post operatively. In Gr. -B. None of the patient had lagophthalmos in down gaze more than $2 \mathrm{~mm}$. 6 cases in Group-A were grossly under corrected and plan for revision surgery. One case in Group-B undergo readjustment of the sling due to over correction may cause exposure keratopathy. It was done within 4 days. 2 cases had exposure keratopathy which was treated with conservatively with lubricant drops and ointment. Post operatively Lid oedema and scar persist more than. 3month in Gr. A. and it resolve much faster in Group B as it is minimally invasive surgery. Bleeding and tissue handling more in Group A and less in Gr-B. Mild nasal peaking was seen 5 cases but it is cosmetically acceptable to the patient.

\section{DISCUSSION}

In this study Surgical approach regarding sever ptosis with poor function ptosis in Group-A Supra maximal placation of LPS (25-30 mm ) and in Gr.-B Tarso frontalis sling by silicon rod used. In unilateral cases we are not interfere. With other healthy eye try to make, symmetry by adjusted the affected eye, lid height in both the group. Beard performed removal of normal LPS from the normal eye make it bilateral ptosis, then bilateral sling surgery ${ }^{12.13}$. Callahan suggested bilateral sling, leaving the normal levator muscle intact. So, the normal eye lid does not move down in down gaze, make the both lid symmetry ${ }^{14}$. Whitnall's sling surgery used alternative with sever ptosis LPS function ranging from 3 to $5 \mathrm{~mm}^{15}$. Here severe ptosis with poor function LPS unilateral cases $(60 \%)$ (24) eyes more than bilateral $16(40 \%)$ cases. Male (62.5. \%) 25, were more involved than female (37.50)15 cases. Blepharophimosis syndrome with bilateral ptosis seen in 2( cases) $5 \%$ In ptotic eye lid LPS Muscle unable to relax that is why upper eye Lid is retracted in down gaze. So the lid lag is more pronounce both in plication Group-A and frontalis sling surgery Gr-B. In down gaze. Both orbital septum and LpS muscle were thinning and cellular infiltration seen during surgery ${ }^{16,17}$. In both the group we performed the ptosis surgery where the average post operative MRD-1 value + $2.68 \pm 0.65$ with brow active position in Group-A and $3.90 \pm 0.55$.Group-B with acceptable cosmetics. Mahmood achieved good results in $87 \%$ of patients with poor LPS again of $2-4 \mathrm{~mm}$ by resection of LPS of $15-26 \mathrm{~mm}^{18}$.Anderson et.al found that Whitnall's sling is the best for LPS action of $3-5 \mathrm{~mm}$ in ptotic eyelid. Material used for sling surgery is silicon rod in his study various material may be used autogenous fascia Lata, proline, silk suture, banked sclera. Silicon rod has definitive advantage of being elastic property and overcome the residual lagophthalmos. Marceline silk is more chance of extrusion and granuloma formation ${ }^{19,20}$. Lid crease incision with plication of (Supra maximal 25-30mm) LPS and fixed over the tarsal plate. This is the advantage of minimum disturbance of lid structure and keeping the LPS insertion intact than LPS resection technique where insertion site is totally detached. In placation procedure if it is failed come back to previous state of lid height, never been complete ptosis, which is possible in LPS resection. ${ }^{21,22,}$ But in sling surgery. If under correction or over correction occur as complication first readjust the sling at the apex of the pentagon at central for head stab incision site ${ }^{23,24}$. But there is gross under correction in this series in plication of LPS Group A $6(\%)$ cases ever maximal plication $(25-30 \mathrm{~mm})$ of LPS performed in respect to tarso frontalis ling with silicon rod Group-B 1 (\%).Group-A needs Re surgery. In this series exposure keratopathy, more cornrow in Group-B that Gr-A. Lid deformity central nothing 5 (\%) more in plication of LPS Gr -A. Nasal picking which cosmetically acceptable more in Tarso frontalis sling' with silicon rod Gr.-B. It is due to synchronise inappropriate lift of sling silicon rod. Can be avoid by meticulous adjustment Lid oedema and scar persist more in Group-A It is due to excessive manipulation of the tissue but it is less in Gr-B. It persists for 2 week as it is minimal invasive surgery. Frost suture retain longer in Group-A for 7 days than Gr-B. 5 days early lid rehabilitation is more in Sling Gr. than Plication Gr. As sling. Surgery is minimal invasive surgery.LPS is minimally handled so rapid rehabilitation is possible. ${ }^{25}$ In respect to uplift of the lid post operatively, comparison between $\mathrm{Gr}-\mathrm{A}$ and $\mathrm{Gr}-\mathrm{B}$ results shows, there was good uplift with brow up and brow down In Group B which is stastically significant $(\mathrm{p}<0.00 .1)$

\section{CONCLUSIONS}

In severe ptosis with poor function LPS Tarso frontalis sling with silicon rod is superior to LPS plication with one year follow up. Because post operatively it maintains very good 
cosmetic lid height with good elastic property during blinking action. As it is minimal invasive surgery early lid rehabilitation is possible. Over all Post operative complication is minimal. It does not require too much anatomical dissection.

\section{REFERENCES}

[1] Kanski JJ. Clinical Ophthatmotogy. Edinburgh: Butterworth-Heineiman 2003: p. 96-7.

[2] Whitehouse GM, Grigg JR, Martin FJ. Congenital ptosis: results of surgical management. Aust N Z J Ophthatmol 1995;23(4):309-14.

[3] Lee MJ, Oh JY, Choung HK, et al. Frontalis sling operation using silicone rod compared with preserved fascia lata for congenital ptosis: a three years followup study. Ophthalmology 2009;116(1):123-9.

[4] Gupta S. Silicon sling frontalis suspension for correction of congenital blepharoptosis. People's J Sci Res 2010;3(1):31-3.

[5] Srinath N, Balaji R, Basha MS. Ptosis correction: a challenge following complex orbital injuries. J Maxillofac Oral Surg 2012;11(2):195-9.

[6] Chang S, Lehrman C, Itani $\mathrm{K}$, et al. A systematic review of comparison of upper eyelid involution ptosis repair techniques: efficacy and complication rates. Plastic Reconstr Surg 2012;129(1):149-57.

[7] Zhong $\mathrm{M}$, Jin $\mathrm{R}$, Li Q, et al. Frontalis muscle flap advancement for correction of severe ptosis under general anesthesia: modified surgical design with 162 cases in China. Aesthetic Plast Surg 2014;38(3):503-9.

[8] Bellinvia G, Klinger F, Maione L, et al. Upper lid blepharoptasty, eyebrow ptosis and lateral hooding. Aesthet Surg J 2013;33(1):24-30.

[9] Cho IC, Kang JH, Kim KK. Correcting upper eyelid retraction by means of pretarsal levator lengthening for complications following ptosis surgery. Plast Reconstr Surg 2012;130(1):73-81.

[10] Cahill KV, Bradley EA, Meyer DR, et al. Functional indications for upper eyelid ptosis and blepharoplasty surgery: report by the American Academy of Ophthalmology 2011;118(12):2510-7.

[11] Bemardini FP, Cetinkaya A, Zambelli A. Treatment of unilateral congenital ptosis: putting the debate to rest. Curr Opin Ophthalmol 2013;24(5):484-7.

[12] Goldberg RA, Lew H. Cosmetic outcome of posterior approach ptosis surgery (an American Ophthalmological Society thesis). Trans Am Ophthalmol Soc 2011;109:157-67.
[13] Philandrianos C, Galinier R, Salazard B, et al. Congenital ptosis: long-term outcome of frontalis suspension using autogenous temporal fascia or fascia lata in children. J Plast Reconstr Aesthet Surg 2010;63(5):782-6.

[14] Berry-Brincat A, Willshaw H. Paediatric blepharoptosis: a 10-year review. Eye (Lond) 2009;23(7):1554-9.

[15] Morris CL, Buckley EG, Enyedi LB, et al. Safety and efficacy of silicone rod frontalis suspension surgery for childhood ptosis repair. J Pediatr Ophthalmol Strabismus 2008;45(5):280-90.

[16] Lelli GJ Jr, Musch DC, Fruech BR, et al. Outcomes in silicon rod frontalis suspension surgery for high-risk non-congenital blepharoptosis. Ophthal Plast Resconstr Surg 2009;25(5):361-5.

[17] Bagheri A, Aletaha M, Saloor H, et al. A randomized clinical trial of two methods of fascia lata suspension in congenital ptosis. Ophthal Plast Reconstr Surg 2007;23(3):217-21.

[18] Khooshabeh R, Baldwin HC. Isolated Muller's muscle resection for the correction of blepharoptosis. Eye (Lond) 2008;22(2):267-72.

[19] Bernardini FP, De Conciliis C, Devoto MH. Miniinvasive ptosis surgery. Orbit 2006;25(2):111-5.

[20] Singh D. Orbicularis plication for ptosis: a third alternative. Ann Ophthalmol (Skokie) 2006;38(3):18593.

[21] Hersh D, Martin FJ, Rowe N. Comparison of silastic and banked fascia lata in paediatric frontalis suspension. J Pediatr Ophthalmol Strabismus 2006;43(4):212-8.

[22] Wong CY, Fan DS, Ng JS, et al. Long-term results of autogenous palmaris longus frontalis sling in children with congenital ptosis. Eye (Lond) 2005;19(5):546-8.

[23] Simon BGJ, Macedo M, Schwarcz RM, et al. Frontalis suspension for upper eyelid ptosis: evaluation of different surgical designs and suture material. Am J Ophthalmol 2005;140(5):877-85.

[24] Mehta P, Patel P, Olver JM. Functional results and complications of Mersilene mesh use for frontalis suspension ptosis surgery. $\mathrm{Br} \mathrm{J}$ Ophthalmol 2004;88(3):361-4

[25] Frueh BR, Musch DC, McDonald HM. Efficacy and efficiency of a small-incision, minimal dissection procedure versus a traditional approach for correcting aponeurotic ptosis. Ophthalmology 2004;111(12):2158-63. 